\section{Agricultura, biotecnologia e movimentos sociais}

\section{Agriculture, biotechnology and social movements}

MOTTA, Renata. Entre controvérsia e hegemonia: os transgênicos na Argentina e no Brasil. Rio de Janeiro, Editora Fiocruz, 2018. 260 pp.

\section{Marcos Paulo Campos (1) \\ https://orcid.org/0000-0002-1189-085X}

(1) Universidade Estadual Vale do Acaraú, Sobral - CE, Brasil. E-mail: marcospaulo_campos@yahoo.com.br.

DOI 10.1590/3510417/20

Recebido Setembro 30, 2019

Aprovado Dezembro 20, 2019

A abordagem das ciências sociais para os temas agricultura, alimentação e movimentos sociais constitui a análise de Renata Motta sobre os transgênicos no Brasil e na Argentina. A obra Entre controvérsia e hegemonia: os transgênicos na Argentina e no Brasil, publicada pela Editora Fiocruz em 2018, é resultado da pesquisa de doutoramento da autora na Freie Universität Berlin (Alemanha), mas não carrega consigo uma linguagem exclusiva a acadêmicos. Ao contrário, o texto tem fluência agradável sem perder a densidade própria à análise sociológica dos conflitos sociais que estão na base do estabelecimento pioneiro de uma bio-hegemonia favorável aos transgênicos na Argentina e da controvérsia política em relação à transgenia no Brasil.

Para lidar com dois casos tão significativos, considerando que a Argentina e o Brasil são os maiores produtores mundiais de cultivos transgênicos, Motta recorreu a um desenho de pesquisa afeito a "sistemas mais similares com resultados diferentes" (p. 45). Essa opção metodológica é justificada pela autora: constrói uma análise centrada nos casos e não nas variáveis, trabalha analiticamente as semelhanças e as diferenças entre os dois casos e promove a identificação das instâncias relevantes na explicação das diferentes trajetórias.
Ao observar os principais produtores de organismos geneticamente modificados (OGMs), Motta percebeu que os dois países da América do Sul ofereciam a melhor similaridade com relação à produção e ao tipo de transgenia autorizada para manejo agrícola, enquanto guardavam profundas diferenças na trajetória constituinte dessas características comuns. A escolha dos casos brasileiro e argentino teve uma orientação teórica de investigação em que se articulam tanto os planos macro, meso e microssociológicos como a análise centrada no ator. Isso tudo se entrelaça na apreensão da qualidade eminentemente política dos debates públicos sobre cultivos transgênicos nos quais se disputam significados coletivos. A autora recusa o individualismo metodológico das pesquisas de opinião pública em favor da corrente teórica cujas imbricaçóes entre democracia e esfera pública embasam fecundas agendas e perspectivas analíticas. O trabalho também considera as conclusóes de estudos anteriores e a constatação do caráter caleidoscópico da pesquisa social sobre transgênicos.

A presença dos movimentos sociais que resistem à bio-hegemonia ou lideram a controvérsia em torno dos transgênicos é interpretada com referências às teorias do confronto político, com destaque para os trabalhos de Sidney Tarrow (2005; 2011), em articulação com os aportes da sociologia rural em diferentes escalas, com o acúmulo da sociologia dos movimentos sociais latino-americanos e com as perspectivas legadas pelos estudos sobre o ativismo transnacional. É justamente essa articulação crítica que permite a Motta balizar adequadamente o impulso global do neoliberalismo à biotecnologia, a regulação e os tratados dos organismos multilaterais, o ativismo transnacional anti-OGMs e a mobilização em escala nacional e local dos movimentos sociais que constituem os amálgamas conflitivos mais relevantes do livro. Contudo, ao dedicar dois capítulos a cada caso e adentrar no plano nacional, o papel do Estado assume importância significativa na constituição das trajetórias diferenciadas que tanto instigaram a autora e a conduziram a debates sobre neoliberalismo na América Latina e sobre kirchnerismo (Svampa, 2008; 2012) e lulismo (Singer, 2012; Nobre, 2013).

O caso argentino é apresentado como aquele no qual o estabelecimento da bio-hegemonia se 
deu, inicialmente, sem impedimentos, passando a contar com resistência social somente em período posterior. Essa não resistência se vinculou ao momento neoliberal dos anos de 1990 na Argentina e à associação entre os cultivos transgênicos, a alta produtividade e a modernização econômica do país. A esse cenário, somou-se a ausência de movimento camponês organizado nacionalmente, considerando que o Movimiento Nacional Campesino Indígena (MNCI) só foi organizado em 2005. Para Motta, o impulso global, em regime de parceria com o Estado nacional, promoveu uma verdadeira revoluçáo biotecnológica na Argentina, cujo custo foi a pecuária em troca dos altos índices de produção na agricultura e da expansão da área plantada. Em 1991, o Estado argentino contava com um órgão para regular a biotecnologia, tendo perfil técnico-científico e sem participação da sociedade civil. Esse caráter assegurou pouca controvérsia pública, em 1996, em torno do uso comercial de sementes de soja transgênica da Monsanto, porque a comunidade científica argentina não contava com resistência significativa à transgenia.

O período da Revoluçáo Verde tardia (p. 64) na Argentina constituiu para a agricultura familiar do país fortes transformaçóes, marcadas pelo aumento das falências, o que impeliu os pequenos proprietários a vender ou alugar suas terras. Segundo Motta, só conseguiram seguir na atividade agrícola aqueles que se capitalizaram e incorporaram tecnologia, ou seja, quem se tornou empreendedor familiar. Isso confirma a inserção de formas empresariais de organização na pequena agricultura argentina com capacidade de alteração dos sentidos tradicionais do processo produtivo. Mais que uma concentração de terra, esse período promoveu uma concentração produtiva.

As mudanças na pequena agricultura não foram a maior contradição experimentada pelo mundo agrário argentino. Em junho de 2002, a organização não governamental Greenpeace lançou um relatório sobre a colheita recorde e o aumento da fome no país, indicando que a produtividade dos cultivos transgênicos não realizava a segurança alimentar que preconizava. Esse relatório foi apresentado em um contexto de intensa crise política na Argentina e de contestação à expansão dos cultivos que se fortalecia regional e nacionalmente.
A crise econômica, a emergência alimentar e a convulsão política que marcaram o início dos anos 2000 na Argentina assistiram também à formação de uma resistência social aos transgênicos, organizada muito mais pelo movimento camponês que pelos agricultores familiares. A construçáo da identidade dos camponeses e dos povos indígenas foi fundamental na reivindicação de uma maneira diferente de se relacionar com a terra e a natureza. Essa reivindicação se apresentou nas açôes de resistência com caráter disruptivo acionadas pelo movimento indígena que visavam impedir despejos forçados. Tais açôes foram acompanhadas de repertórios mais institucionais para a obtenção de uma lei de sementes anti-OGMs. Quando a fumigação de agrotóxicos se tornou mais intensa, os pobres rurais constituíram formas de organização e protesto que ampliaram a conflitualidade em torno dos cultivos transgênicos argentinos.

O cruzamento das questóes agrária, de saúde, evidenciada pelo aumento dos casos de câncer nas regiōes fumigadas, e de preservação ambiental e a aliança entre os movimentos sociais locais e as organizaçóes de ativismo transnacional culminaram na Lei das Florestas, de 2007, reconhecida pelos integrantes da resistência argentina como uma conquista do processo de mobilização. Nesse contexto, a construção de um mapa epidemiológico com base nos bairros atingidos pela fumigação nos pampas assume destacada importância no trabalho de Motta, porque significa a produção contra-hegemônica de conhecimento e uma das dimensóes mais criativas das forças sociais contrárias à imbricação entre economia e ciência táo bem representada pelo modelo biotecnológico. Para a autora, essa ação, promovida pelo movimento Mães de Ituzaingó, aproveitou a convivência nos bairros como base para a construçâo dos saberes com os quais se fez a luta política anti-OGMs. A mobilização das mães ainda agregou à luta social contra os transgênicos a questão de gênero e o forte simbolismo das mulheres na política argentina. Os laços comunitários permitiram às mulheres o acesso a situaçôes calamitosas enfrentadas pelos adoecidos da fumigação, constituindo um discurso sobre as consequências da bio-hegemonia para a saúde humana, com base em evidências sensíveis. Isso se somou à emergência de posiçóes críticas aos transgênicos no 
campo científico argentino, sendo o caso de Andrés Carrasco, chefe do Laboratório de Embriologia Molecular da Universidade de Buenos Aires, o mais relevante para a análise de Motta.

Os fatores favoráveis aos críticos da transgenia sofreram reação da coalizão pró-OGMs, que possuía forte penetração na burocracia estatal argentina e apoio midiático. A crise econômica e política do início dos anos 2000 encontrou uma solução com a taxação da exportação de grãos, considerando que seus preços experimentavam tendência de alta no mercado internacional, e a ascensão de Néstor Kirchner à presidência. A alta produtividade dos cultivos transgênicos estava, portanto, na base da recuperação das finanças e dos investimentos públicos e da superação das condiçóes de pobreza e fome do país, constituindo, ao lado da reação pró-OGMs, um forte entrave ao avanço das reivindicaçóes contrárias ao modelo neoliberal agroalimentar biotecnológico.

Motta narra as ocorrências da "batalha rural" de 2008 na Argentina, quando a recém-eleita Cristina Kirchner elevou as taxas sobre a exportação de grãos, como uma evidência do enraizamento da bio-hegemonia no mundo agrário do país. $\mathrm{Na}$ frente contrária à taxação, pequenos produtores e grandes exportadores ficaram do mesmo lado, pois esperavam uma safra recorde e não queriam dividir seus ganhos com a arrecadação estatal. A classe média urbana colaborou com essa frente por meio de protestos públicos, e tudo isso culminou em uma votaçáo no Parlamento com resultado negativo para a continuadora do kirchnerismo. Apesar do embate, a soja transgênica seguiu sendo promovida pelo governo argentino, configurando o que Motta considera ser a consolidação de uma política de Estado agroalimentar biotecnológica, a despeito das críticas ao neoliberalismo e da retórica progressista dos Kirchner.

O caso brasileiro é percebido no livro de Motta como aquele em que a controvérsia em torno dos transgênicos se apresentou desde as primeiras açôes para a inserção da tecnologia nos cultivos nacionais. Isso se deu porque, segundo a autora, desde a redemocratização, a intensa mobilização dos movimentos sociais rurais em torno da reforma agrária constituiu uma forte frente opositora aos OGMs. Diferentemente do caso argentino, em que não havia mobilização rural significativa quando ocorreu a chegada da biotecnologia, agricultores familiares, populaçóes sem terras e ativistas pela agroecologia no Brasil promoveram um repertório de ações capaz de catapultar as críticas à transgenia aos meios de comunicação mais influentes do país. Isso se somou a outras três razóes listadas pela autora. A primeira delas diz respeito às divisóes dentro da comunidade científica brasileira, cujo histórico apresenta muitas relaçóes com o movimento ambientalista. A segunda razão está na consolidação do ambientalismo no Brasil ocorrida nos períodos anterior e posterior à Eco-92, por meio de aportes financeiros e profissionalização de agentes e instituiçốes envolvidos na luta ambiental. A terceira e última razão se encontra no amplo desejo de engajamento por uma sociedade em processo de reabertura de suas liberdades democráticas. Em todos os setores, no início dos anos de 1990, assistia-se à ampliação dos processos de participação. A controvérsia sobre a biotecnologia se deu em um momento favorável ao debate público a respeito das questôes ambientais na sociedade brasileira.

Uma ocorrência no plano legal determinou a capacidade de interferência do movimento social em favor de decisóes anti-OGMs na década neoliberal brasileira. No contexto do governo de Fernando Henrique Cardoso (1995-2002), uma ação judicial do Instituto Brasileiro de Defesa do Consumidor (Idec), apoiada pelo Ministério Público, contra a soja transgênica culminou em uma liminar, obtida no mesmo dia da interpelação do Idec, que se configurou como uma moratória legal, praticamente, atrasando a entrada da biotecnologia para a década seguinte. Nesse sentido, a resposta do poder judiciário colaborou para a ampliação da percepção pública do tema dos transgênicos com base no princípio da precaução. Isso porque a ação judicial teve significativa cobertura midiática, ampliando o alcance do discurso da coalizão anti-OGMs. A moratória estabelecida pela liminar só teve fim em 2005 com a aprovação da Lei de Biossegurança, no contexto do governo nacional do Partido dos Trabalhadores (PT), iniciado com a eleição de Luiz Inácio Lula da Silva, em 2002.

Segundo Motta, a chegada do PT ao poder alimentou expectativas amplas nos movimentos sociais rurais em torno da reforma agrária e do fortalecimento 
de políticas para a agroecologia, em detrimento da proposição do agronegócio, cada vez mais afeito à transgenia e à produção em larga escala de grãos para o mercado internacional. Essa expectativa náo era infundada. $\mathrm{O}$ apoio da bancada parlamentar petista à controvérsia contra os OGMs ao longo dos anos de 1990 e a perspectiva de tornar o Rio Grande do Sul uma área livre de transgênicos, trazida ao debate público na eleição de Olívio Dutra (PT), em 1998, ao governo gaúcho, fizeram a experiência governativa nacional petista ser percebida como uma aliada pela coalizão contrária aos transgênicos. E mais, no processo eleitoral, a campanha Por um Brasil Livre de Transgênicos, realizada por ampla aliança entre movimentos rurais, organizaçóes náo governamentais ambientalistas e consumidores organizados, conseguiu inserir no programa de governo do candidato petista a perspectiva de assegurar a moratória aos OGMs até que estudos conclusivos fossem realizados. No entanto, as mudanças ocorridas na posição partidária e, sobretudo, as decisóes do governo de Lula da Silva são elementos bastante significativos para o avanço dos transgênicos no Brasil na década seguinte ao estabelecimento da bio-hegemonia na Argentina.

As mudanças de posição do PT no poder se relacionam com a renovaçáo do pacto de economia política em favor do agronegócio que, desde 1999, recebe forte investimento federal para viabilizar sua produção para o mercado externo, onde encontrou compradores de grande porte, principalmente, entre as economias em ascensão, como a chinesa. Essa relevância da agroexportação devolvia em arrecadação aquilo que era necessário para equilibrar as contas públicas quando a paridade real/dólar e a engenharia de política econômica do plano de estabilização monetária ruíram. Esse pacto de economia política (Delgado, 2010) estava em pleno vigor quando o governo Lula estabeleceu sua agenda nacional com reformas distributivistas sem confronto com o capital (Singer, 2012). O caminho de baixa conflitualidade com o poder econômico foi expresso, no plano da controvérsia em torno dos transgênicos, por meio da permissão, apesar da oposição de movimentos sociais, setores petistas e parte do próprio governo, do cultivo da soja transgênica que havia sido, inicialmente, traficada da Argentina por fazendeiros da fronteira entre os dois países.

O elemento definidor da construção hegemônica dos transgênicos no Brasil, segundo a obra de Motta, está na dependência da bancada ruralista que o governo Lula passou a experimentar desde o escândalo de corrupção conhecido como "mensaláo", em 2005. A acomodação institucional necessária à aprovaçấo da agenda prioritária do governo no Congresso Nacional, que incluía o combate à fome e à pobreza, somada à valorização internacional dos preços dos grãos vendidos pelo país, que significava maior arrecadação, estiveram na base das decisóes favoráveis à transgenia no Brasil durante os governos do PT (2003-2016). A liberaçáo do milho transgênico em 2008 e a não edição de posiçóes críticas por parte do partido, embora alguns integrantes tenham mantido relaçôes com a coalizão anti-OGMs, são evidências da admissão dos pleitos da coalizão agroalimentar biotecnológica por parte do governo Lula como uma "política do fato consumado" (p. 148). Isso definiu um resultado aproximado ao argentino, a despeito da controvérsia ter se apresentado desde o início e ter sido capaz de retardar a inserçẫo dos OGMs nos cultivos brasileiros.

Ao analisar os casos de Brasil e Argentina, Motta demonstra em sua obra que os movimentos sociais anti-OGMs e os repertórios mais tradicionais de mobilizaçáo utilizam conhecimento científico contrahegemônico e de contestação a avaliaçôes oficiais de risco para viabilizar suas reivindicaçóes. Esses discursos de validade cognitiva, muitas vezes, não são enfrentados no plano propriamente científico, padecendo de estigmatização e ridicularização promovidas pela coalizáo da biotecnologia. Tanto no caso brasileiro como no caso argentino o alcance dos movimentos dependeu da interpretaçáo jurídica e política no plano dos direitos e não do reconhecimento da validade do conhecimento contra-hegemônico produzido. A autora aponta que, apesar da novidade no plano das elaboraçóes, foram os repertórios de associação entre luta social e interpretação jurídico-política que asseguraram as vitórias, ainda pequenas, da coalizão anti-OGMs nos dois casos. O tamanho da produçáo transgênica no Brasil e na Argentina indica facilmente o quão reduzido foi o 
alcance das reivindicaçóes dos movimentos sociais. No entanto, o estudo demarca que essas mesmas reivindicaçóes inseriram no debate público desses países importantes núcleos críticos que podem ser ampliados em oportunidades políticas futuras. Também são a discursividade em que se reúnem experiências agroecológicas e alianças de movimentos sociais significativas no plano das alternativas às quais, em momento de maior consciência social e política dos riscos da transgenia, se pode recorrer.

\section{BIBLIOGRAFIA}

DELGADO, Guilherme. (2010), "A questão agrária e o agronegócio no Brasil", in M. Carter (org.), Combatendo a desigualdade social: o MST e a reforma agrária no Brasil, São Paulo, Editora Unesp, pp. 81-112.
NOBRE, Marcos. (2013), Imobilismo em movimento: da abertura democrática ao governo Dilma. São Paulo, Companhia das Letras.

SINGER, André. (2012), Os sentidos do lulismo: reforma gradual e pacto conservador. São Paulo, Companhia das Letras.

SVAMPA, Maristela. (2008), Cambio de época: movimientos sociales y poder político. Buenos Aires, Clacso/Siglo XXI.

SVAMPA, Maristela. (2012), "Consenso de los commodities, giro ecoterritorial y pensamiento crítico en América Latina”. Revista del Observatorio Social de América Latina, XIII (32): 15-38.

TARROW, Sidney. (2005), The new transnational activism. Nova York, Cambridge University Press.

TARROW, Sidney. (2011), Power in movement: social movements and contentious politics. Nova York, Cambridge University Press. 